This report has been reproduced directly from the best avallable copy.

Avallable to DOE and DOE contractors from the Office of Scientific and Techntcal information, P.O. Box 62, Oak Ridoe, TN 37831; prices avallable from (815) 576-8401, FTS 626-8401.

Avalable to the public from the National Technical Information Service, U.S. Department of Commerce, 5285 Port Royal Rd., Springtield, VA 22161.

This report was prepared as an account of work sponsored by an aconcy of the United States Government. Notther the United States Government nor any agency thereof, nor any of their employees, makes any warranty, exprees or implied, or secumes any logal liability or responalbility for the accuracy, com plesenves, or usofulneses of any information, apparatus, product, or proceses diecloeed, or represents that the use would not intringe privately owned rights. Reterence herein to any epecific commercial product, proceses, or service by trade namo, trademark, manufacturer, or otherwise, dose not necesearty consth. tute or imply he endorsement, recommendation, or favoring by the United States Government or any agency thereof. The views and opinions of authors expreseed herein do not necessarity state or reflect those of the United States Government or any agency thereot. 


\title{
THE DEMAND-SIDE MANAGEMENT PROGRAM DEVELOPMENT PROCESS - A UTILITY PERSPECTIVE
}

\author{
AMY K. WOLFE AND N. EVELIN YOURSTONE*
}

March 1992

Sponsored by

Office of Conservation and Renewable Energy

U.S. Department of Energy

OAK RIDGE NATIONAL LAEORATORY

Oak Ridge, Tennessee 37331

managed by

MARTIN MARIETTA ENERGY SYSTEMS, INC.

Under Contract No. DE-AC05-840R21400

for the

U.S. DEPARTMENT OF ENERGY

\footnotetext{
*Consultant, Albuquerque, New Mexico
} 


\section{TABLE OF CONTENTS}

EXECUTIVE SUMMARY $\ldots \ldots \ldots \ldots \ldots \ldots \ldots \ldots \ldots \ldots \ldots$

LISTS OF FIGURES AND TABLES $\ldots \ldots \ldots \ldots \ldots \ldots \ldots \ldots \ldots$ vii

1. INTRODUCTION $\ldots \ldots \ldots \ldots \ldots \ldots \ldots \ldots \ldots \ldots \ldots \ldots \ldots \ldots \ldots \ldots \ldots$

2. CONTEXT OF DSM PLANNING $\ldots \ldots \ldots \ldots \ldots \ldots \ldots \ldots \ldots \ldots, 3$

2.1 ORGANIZATIONAL CHARACTERISTICS $\ldots \ldots \ldots \ldots \ldots \ldots 3$

2.2 EXTERNAL INFLUENCES $\ldots \ldots \ldots \ldots \ldots \ldots \ldots \ldots \ldots$

3. OVERVIEW OF PROGRAM DEVELOPMENT .............. 9

3.1 TECHNOLOGY- VERSUS CUSTOMER-ORIENTATION $\ldots \ldots \ldots 9$

3.2 STAGES IN THE PROCESS $\ldots \ldots \ldots \ldots \ldots \ldots \ldots \ldots \ldots \ldots, 12$

3.3 BASIC CHARACTERISTICS OF THE PROCESS $\ldots \ldots \ldots \ldots \ldots 17$

4. SELECTED DETAILS OF THE PROGRAM DEVELOPMENT PROCESS $\ldots 19$

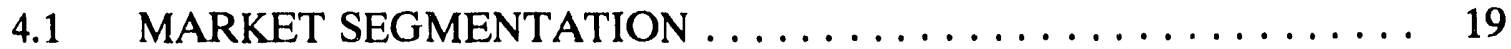

4.2 PROGRAM PARTICIPATION $\ldots \ldots \ldots \ldots \ldots \ldots \ldots \ldots \ldots, 21$

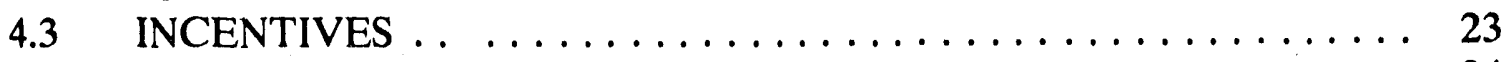

4.4 PROGRAM EVALUATIONS $\ldots \ldots \ldots \ldots \ldots \ldots \ldots \ldots \ldots \ldots 24$

5. SUMMARY AND RECOMMENDATIONS $\ldots \ldots \ldots \ldots \ldots \ldots \ldots \ldots \ldots$

ACKNOWLEDGMENTS $\ldots \ldots \ldots \ldots \ldots \ldots \ldots \ldots \ldots \ldots \ldots \ldots \ldots \ldots \ldots \ldots \ldots$

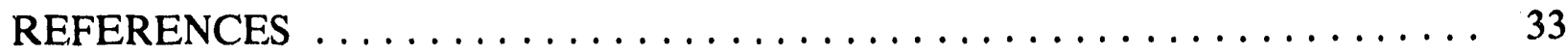

APPENDIX A. DESCRIPTION OF PARTICIPATING UTILITIES . . . . . 37

APPENDIX B. RESEARCH METHODS $\ldots \ldots \ldots \ldots \ldots \ldots \ldots \ldots \ldots \ldots \ldots$ 


\section{EXECUTIVE SUMMARY}

This report describes the findings from an Oak Ridge National Laboratory (ORNL) study of the demand-side management (DSM) program development process of 13 electric utilities.

The study is based on lengthy telephone interviews with utility personnel, interviews made during site visits to three utilities, documents sent by utilities on their process, and published literature. The telephone interviews followed a protocol that focused primarily on obtaining an overview of the DSM program development process and, secondarily, on uncovering the bases for making decisions.

Because the study is exploratory, it does not draw conclusions about an optimal planning process. Rather, this study allows outsiders to peer inside the DSM planning "black box" and gain insight into the factors that motivate and affect DSM programs from the utility's perspective. The study also provides utility planners information against which to compare their own beliefs, perceptions, and motivations about DSM planning.

Two types of DSM program development were discerned. Utilities can be categorized according to those that have a technology orientation and those with a customer orientation. Utilities characterized as technology-oriented generally approach DSM from an engineering perspective, emphasizing the technical feasibility and the energy impacts of various technologies. Utilities characterized as customer-oriented emphasize the importance of customer needs and attempt to offer DSM programs that satisfy those needs. These two orientations most noticeably affect the stage in the program development process in which customer needs and technologies are considered. For technology-oriented utilities, customer needs are considered after technologies are selected and programs have been designed preliminarily. For customer-oriented utilities, customer needs are considered at the very beginning of the process; programs are designed to fill those needs.

In addition to identifying two types of DSM program development, this study characterized DSM planning as iterative and interactive; variable over time and at a given time, depending on the program developers and market being served; and flexible and adaptive. The impacts of organizational factors, external influences, market segmentation, estimates of program participation, incentives, and program evaluations upon program development also were explored.

Lastly, key decisions about the planning process that utilities new to DSM must make were identified. The decision points are whether to have a technology- or a customeroriented process; what the functional responsibilities of the demand-side planning group should be (e.g., will it implement and evaluate programs in addition to planning them); what role outside consultants will play in designing programs and developing plans; the location of the demand-side planning group in the organization's reporting structure; to offer a few comprehensive programs or many specific programs; and whether to use an interdepartmental team or solely demand-side planning personnel to develop programs. 
The primary recommendation regarding the DSM program development process is for utilities to document that process in greater detail than currently is done. In particular, utilities evaluating their current process or beginning DSM programs would benefit from documentation and standardization. The documentation should outline the steps in the process, indicate the broad rules that inform judgments, ${ }^{1}$ and depict where interactions and iterations are likely. This documentation is needed to ensure replicability of the planning process and its results; provide a focus for analyzing and improving the process; inform outsiders (regulators, nonutility parties, and consumer groups) about the process; share information with other utilities in a readily understandable form; and bolster the status of DSM within utilities. Recommendations also were made to conduct follow-on research that explores the implications of different approaches to DSM program development and that investigates the program development process from the perspectives of nonutility parties.

\footnotetext{
${ }^{1}$ Such rules would go beyond "intuition" and "experience." For example, a rule might state that when a single measure is not cost effective, but it is closely aligned with cost-effective measures that are combined in a program, and it is a measure that is likely to improve customer satisfaction, that measure may be included in a DSM program.
} 


\section{LIST OF FIGURES}

Fig. 2.1. Generic utility reporting structures $\ldots \ldots \ldots \ldots \ldots \ldots \ldots \ldots \ldots, 3$

Fig. 3.1. Schematic diagram of technology-oriented

DSM program development process $\ldots \ldots \ldots \ldots \ldots \ldots, 10$

Fig. 3.2. Schematic diagram of customer-oriented

DSM program development process $\ldots \ldots \ldots \ldots \ldots \ldots \ldots 11$

Fig. A.1. Geographic location of participating utilities $\ldots \ldots \ldots \ldots \ldots \ldots, 38$

\section{LIST OF TABLES}

Table 4.1. Selected market segments reported by respondent utilities $\ldots \ldots \ldots 20$

Table 5.1. Key decisions to be made about the DSM

program development process $\ldots \ldots \ldots \ldots \ldots \ldots \ldots \ldots 28$

Table A.1. Utilities participating in this study $\ldots \ldots \ldots \ldots \ldots \ldots \ldots \ldots \ldots$

Table B.1. Topics mentioned in initial letter .................. 41

Table B.2. Specific topics addressed in telephone interviews $\ldots \ldots \ldots \ldots \ldots 42$ 


\section{INTRODUCTION}

$\mathrm{DSM}^{2}$ has gained prominence in the last decade as a mechanism for reducing the need to build additional power plants, to save energy, and to meet customer needs. Much of the literature pertaining to DSM analyzes theoretically or empirically its potential to compete with supply-side resources, describes various technologies, discusses its incorporation in integrated resource planning, or evaluates the results of demand-side technologies or programs. The goals of these studies create a situation in which authors largely are able to ignore the question, "how is a DSM program developed?" In contrast, this report starts with that question and focuses on the processes, data, and judgments used to design DSM programs. Neither demand-side technologies nor resulting plans are the focus of this report; instead, the product (i.e., DSM programs) is distinguished from the process (e.g., development, implementation, and evaluation) involved in obtaining demandside resources. This study focuses narrowly on the program development process as perceived by utilities participating in the process. Thus, investigation centered primarily on how utility employees gather and use data, the bases for their judgments, and how these factors interact in the development of DSM programs.

This study is exploratory; its goals are to describe the overall picture of how utilities develop their DSM programs and to discuss some components of that process in detail. No attempt is made to evaluate the effectiveness of different patterns of program development for two reasons. First, to evaluate the effectiveness of a process, that process must be documented. This report therefore is a prelude to evaluation research. Second, the appropriate measures of effectiveness are not readily apparent. Should one gauge success according to the cost-effectiveness of programs, public and regulatory acceptability of programs, the coherence of programs, the speed with which programs are developed, or the organizational and functional ease with which programs are developed? Clearly, before attempting to evaluate the effectiveness of various DSM program development strategies, the meaning of effectiveness requires serious consideration.

In describing DSM program development processes, this study builds on an earlier ORNL study (Hill, Hirst, and Schweitzer 1991). That study described a conceptual framework for DSM analysis that consisted of the following three parts: (1) technology identification and screening, (2) program identification and screening, and (3) demand- and supply-side resources integration. It is the second step in the process outlined by Hill, Hirst, and Schweitzer that is the focus of the present study. This step encompasses numerous components, analyses, and decisions. One goal of the study reported here was to disaggregate the program development stage of the DSM analysis process to show in detail how programs are developed.

In addition to contacts with utilities, literature was searched for information about the DSM program development process. In general, DSM reports and studies focused on

\footnotetext{
${ }^{2}$ For definitions of key DSM-related terms, see Hirst and Sabo 1991.
} 
technical aspects of DSM, such as the technologies available and economic tests (NARUC 1988); specific components of DSM programs such as incentives (Holt 1991; Michaels et al. 1991; and Robinson et al. 1991); program descriptions (EPRI 1989); integration of demandand supply-side resources (Clarke 1989; Schweitzer, Yourstone, and Hirst 1990; Schweitzer, Hirst, and Hill 1991); the collaborative process (Cohen and Chaisson 1990; Cowell 1990; Wall and Giffin 1990; and Raab and Schweitzer 1992); and forecasts of demand-side program impacts (Hirst 1991; New York State Energy Research and Development Authority 1990). Few references described the DSM program development process (Hill, Hirst, and Schweitzer 1991; Gellings, Hirshberg, and Williams 1986). These descriptions were too simplified for the purposes of this study; program development often was relegated to one "develop program" box.

In part, this study aims to uncover assumptions utilities make in the process of DSM program development and the underlying bases for those assumptions. It therefore seems fair to state the assumptions made in the preparation of this report.

Primary among those assumptions is that the program development process can be formalized and docuinented in writing, even though the process includes subjective decision making activity. Whether or not utilities document the process, it was assumed that the structure of the process can be documented. Thus, from the beginning of the research, patterns in development processes were assumed to exist and, when otherwise nonexistent, the authors created flow charts to represent them.

A methodological decision was made to stuay' two types of utilities: (1) those experienced in DSM program development and (2) those that were very new to the process. $^{3}$ This assumption was based on the belief that better and more credible information would be obtained from experienced utilities than from utilities with less experience. Experienced utilities would better be able to describe the process clearly to an outsider. At the same time, utilities new to the process would more readily recall the decisions made when deciding upon the process and would have a shorter and less complicated "history" that would be easier for outsiders to understand.

The next three chapters present the findings of this study. Chapter 2 discusses the effects of the utility's organizational structure and external influences on the DSM program development process. Chapter 3 describes the program development process as well as the major approaches to DSM program development used by the utilities in the sample. Chapter 4 provides detail on selected topics germane to program development (e.g., how participation rates are estimated). Chapter 5 presents a summary of the renort and recommendations. Lastly, Appendix A describes the utilities that participated in the study and Appendix B details the methods used to conduct this study.

\footnotetext{
${ }^{3}$ Unfortunately, no utilities that were new to the DSM program development process participated in the extensive telephone interviews that constituted the majority of this research endeavor.
} 


\section{CONTEXT OF DSM PLANNING}

This chapter describes the major parameters influencing DSM planning. It focuses on the effects of two factors - utility organizational characteristics and external influences - on the DSM program development process.

\subsection{ORGANIZATIONAL CHARACTERISTICS}

This research identified four areas in which a utility's organizational structure may influence the plan...ing of demand side programs significantly: (1) the functional placement of the planning department within the company's organizational structure, (2) the tasks for which the demand-side planning group is responsible, (3) upper management participation, and (4) the functional and organizational relationship between generation and demand-side planning. The great diversity of approaches to the organizational placement of demand-side planning reflects the relative inexperience of utilities in this area relative to supply-side planning. Much restructuring and reorganization of DSM activities has occurred; and there are many uncertainties to which demand side programs are subjected. Respondents raised questions about the importance of demand-side activities to, and the acceptance of these activities by, others in the utility. While respondents generally wanted DSM to be viewed as a resource like any supply-side resource, it was clear that this "equal status" typically has not been achieved in practice, though some respondents believe it is achieved at the planning level.

The organizational location of the demand-side planning department within a utility seems to influence the planning process. Figure 2.1 depicts three generic types of organizational structures observed among utilities participating in this study. The major difference among the structures is a reporting channel to customer service (often through

A.

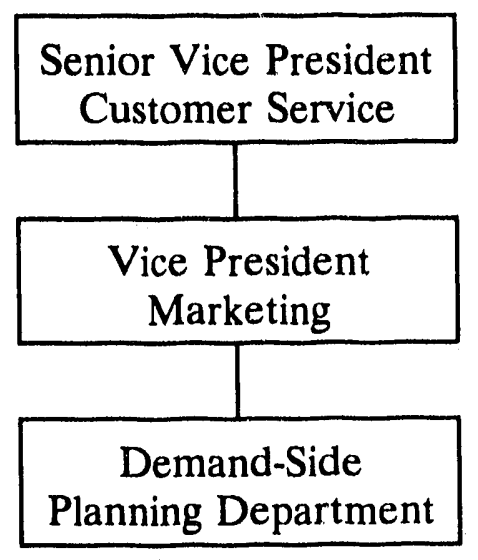

B.

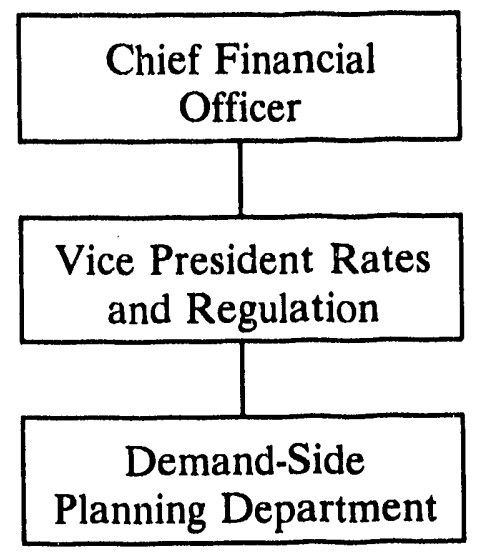

C.

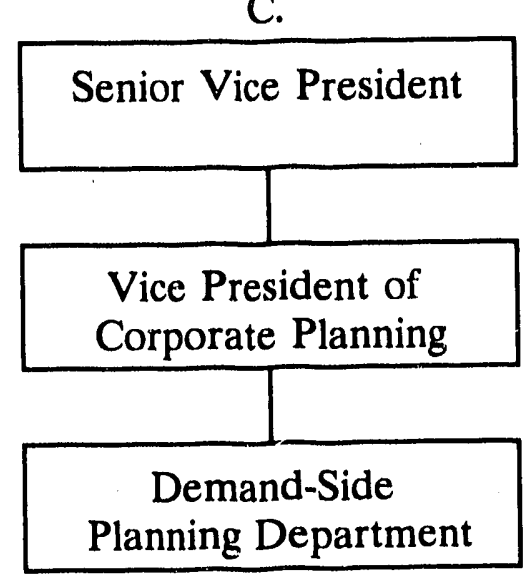

Fig. 2.1. Generic utility reporting structures. 
a marketing department) versus a reporting channel that ultimately leads to a chief financial officer (perhaps through a rates department) versus a reporting channel to overall planning. Most of the utilities sampled do not have one group that is responsible for total resource planning (demand- and supply-side). Exceptions include utilities whose demand-side and supply-side planning groups report to the same vice president (e.g., Boston Edison) and utilities with a single department that has responsibility for both demand-side and supply-side planning (e.g., Green Mountain Power).

A notable difference among utilities is the location of the DSM planning department relative to the department that is responsible for DSM marketing. In some utilities (e.g., Central Maine Power) DSM planning is located within a larger marketing organization, while at other utilities (e.g., Duke Power) the marketing department is separate. At Central Maine Power, discussions of program development include marketing concepts such as target markets, consumer research, psychographics, and removing market barriers. In contrast, although a representative from the marketing department works on a team with the demand-side planning group at Duke Power, the marketing organization is likely to become fully involved only later in the program development process, at the pilot program or implementation stages.

These different reporting structures reflect utility attitudes towards demand-side progranis. Some utilities view demand-side programs as excellent vehicles with which to earn customer loyalty and provide service; such programs provide a much less impersonal way of supplying customers' energy needs than power plants and distribution systems. The dominant role played by customer service and marketing groups in these utilities is not surprising. At utilities where demand-side activities are overseen by financial and regulatory vice presidents, the program development emphasis appears to be on analysis and justification of costs. Lastly, when demand-side planning is part of overall corporate planning at a utility, the focus centers on the plans rather than on program delivery.

Another organizational relationship that varies among the utilities studied is the location of the evaluation department relative to the planning department. Utilities that evaluate their programs generally conduct both process (focusing on delivery mechanisms and administration) and impact evaluations (focusing on outcomes, such as energy and demand savings). At both Central Maine Power and Boston Edison, as examples, the evaluation group is administratively separate from the planning and marketing groups. This separation occurred recently at both utilities, and was implemented to allow the evaluation department to function as an independent auditor. Other utilities (e.g., Madison Gas and Electric, New England Electric System, and Seattle City Light) incorporate evaluation into the overarching planning department. There seems to be a connection between the organizational proximity of planners and evaluators and the rapidity and ease with which evaluators' suggested changes to programs are accepted by planners.

Planners and implementors are linked organizationally at some utilities (e.g., Seattle City Light) under broad labels such as "Energy Management Services" or "Demand-Side Resources Division." Even when the departments are not combined, one utility found that simply moving the implementors physically next to the planners improved the planning 
process by easing and increasing communications between the groups. Often, however, implementors of DSM programs constitute a separate department from the program developers (e.g., Central Maine Power, Duke Power, New England Electric System, and Puget Power). Implementors and planners sometimes report to the same vice president (e.g., Central Maine Power, New England Electric System, and Puget Power); in other cases there is a different reporting structure (e.g., Duke Power).

Two other organizational variations are notable, but tangential to this study. First is the placement of load forecasting and load research departments relative to demand-side planning departments. The demand-side planning group at Union Electric includes load forecasting and load research, while such departments are independent at utilities such as Puget Power. The organizational separation of departments may inhibit the ease and frequency of communication between departments, but it does not halt communication.

The second variation, more important to integrating resource options than to DSM program development, is the relationship between demand-side and supply-side planning departments. Some respondents described the need to gain acceptance for demand-side programs from other areas in the company because the concept is new relative to supplyside planning and because DSM sometimes is vieweci as receiving special treatment. The physical and organizational placement of demand-side departments relative to supply-side departments sometimes was thought to contribute to the utility's overall attitude toward DSM. For instance, the close physical proximity of demand-side and supply-side personnel at New England Electric System was seen to enhance the interactions between departments, and to aid the process of integrating resources.

Some utilities effectively operate within matrix- as well as line-organizations. This situation was most apparent among utilities taking a team approach to DSM program development (e.g., Alabama Power, Central Maine Power, Duke Power, and Potomac Electric Power). Teams typically include planners, implementors, marketers, and evaluators. In some cases, teams also include people external to the utility, such as representatives of environmental groups, customers, and contractors. One utility adopted a team approach after discovering that concentrating its program development efforts solely in the planning group was not ideal. Two major benefits were reported to result from the shift to a team approach. First, there was increased vuy-in to the programs throughout the company. Second, additional issues became a part of the program development process. As an example, the inclusion of distribution system issues within the planning team's purview is helping to shift the target of DSM programs from market segments to distribution system stress points.

DSM program design teams illustrate how organizational structure occasionally may fail to reveal the nature of the interactions between organizational components. Another example is the role of upper management in the program development process. Showing that a department reports to a vice president does not indicate the extent to which upper management plays a role. Few respondents mentioned upper management involvement in the DSM program development process, perhaps because involvement may have been minimal. When mentioned, upper management influences on the program development 
process took several forms beyond reviewing and approving programs. First, upper management may influence the process by setting constraints. For example, one respondent said that upper management defines and outlines the company's limitations ("here's the organization and its resources"). Second, upper management interaction with the demand planning group may be limited and ad hoc. Third, upper management may play a continuing, active, and direct role in program development.

\subsection{EXTERNAL INFLUENCES}

Factors external to electric utilities also affect the DSM program development process. The four external influences mentioned most frequently by respondents were the following: (1) use of consultants, (2) collaboration, (3) economic conditions, and (4) regulatory pressures.

Coincidentally, three of the utilities studied used one consulting firm, in developing their DSM programs. Reasons for using a consultant included the lack of resources and expertise within the utility, the desire to take advantage of consultants' experience, and to meet deadlines for plan development that were imposed on the utility. While the use of a consultant changes the program-development players, consultants do not seem to alter the process of program development substantially. Using outside firms may involve using some of the consultants' assumptions and practices instead of those generated by the utility. As an example, four plans produced by one consulting firm were reviewed for this study. Each of those plans used a technology-oriented approach to program development. Marketing and implementation inputs are sought only after DSM options have been screened and bundled into programs. This approach markedly contrasts to team approaches that include marketing and implementation inputs once a demand-side option (DSO) is chosen for consideration.

Collaboration also does not appear to alter the DSM program development process significantly. Several respondents mentioned that collaboration slows the process. One utility mentioned that collaboration adds confusion to the process and politicizes the development of programs. Politicization occurs when programs are designed to meet the agendas of interest groups rather than to meet more purely economic-based criteria. Lastly, collaboratives can reduce the flexibility utilities have to design their programs. For example, several utilities were pressured by collaborators to pay $100 \%$ of the cost of conservation. Other researchers, however, have emphasized the usefulness of collaboratives in enhancing the planning process (Cohen and Townsley 1990; Raab and Schweitzer 1992).

Local and regional economic conditions can affect the program development process by altering avoided costs and by influencing the degree to which public attention is focused on the programs a utility offers. When avoided costs are high, many cost-effective programs can be implemented. When avoided costs drop, as they have in New England recently, costeffectiveness is harder to achieve. One respondent in this situation reported the need for increased accuracy in planning projections (peoples' jobs and welfare are or. the line) as well as the need for faster program review to ensure that programs remain economically viable. 
Also, when regions experience economic difficulties, the public may criticize utility expenditures on DSM programs. One utility was criticized by its customers for offering rebates for purchasing energy-efficient devices rather than crediting customers' bills.

Legislative and regulatory pressures and incentives typically affect the outcomes of the program development process more than the process itself. ${ }^{4}$ For instance, the Iowa legislature has stipulated that electric utilities must spend two percent of their revenues on cost-effective DSM programs. In other states, financial incentives are offered for effective DSM performance. Such measures increase a utility's impetus to offer programs, but they do not alter the steps in the program development process. Utilities also try to influence the regulatory arena to make their program development process more efficient. At least two utilities that participated in this study have worked with their regulators to streamline the review process, enabling the utilities to introduce programs more smoothly. One utility's public utility commission agreed to review preliminary program proposals. This preliminary review eliminates the need to expend the time and resources necessary to develoj full-scale programs before receiving any indication of their acceptability to the commissioners. Another utility has worked with collaborators to modify regulatory treatment of DSM programs.

${ }^{4}$ One reviewer of this report suggested that regulatory requirements may provide the impetus for utilities to take either a customer- or technology-oriented approach to program development. 


\section{OVERVIEW OF PROGRAM DEVELOPMENT PROCESS}

As stated in the Introduction, this report assumes that the DSM program development process can be documented. The varying patterris of DSM program development discussed in this chapter were discerned primarily from interviews and secondarily from documents supplied by the utilities (see Appendix B). Lengthy telephone interviews were conducted with knowledgeable people at 13 utilities and one consulting firm; face-to-face interviews also were conducted during three site visits.

Analyses of written and interview materials revealed two different approaches to the DSM program development process. These approaches, which result in varying stages in the program development process, are generalized and depicted in Figs. 3.1 and 3.2. This chapter discusses the two primary approaches to DSM planning, the stages of the progi am development process, and basic features $r_{i}$ that process.

\subsection{TECHNOLOGY- VERSUS CUSTOMER-ORIENTATION}

Each utility that participated in this study described a different DSM program development process. Nevertheless, these processes can be categorized into two groups that describe utilities' preferred approaches to DSM program development, namely a technology or a customer-orientation (Figs. 3.1 ;nd 3.2). "Technology-orientation" refers to those utilities with a technology-delivered based approach to plan ning, while "customer-orientation" reflects a market-needs approach. Some utilities with lengthy DSM experience have shifted from a technology-orientation to a customer-orientation over time, perhaps because they are engaged in very little new program development. These experienced utilities focus mainly on changing their program delivery.

The distinction between technology- and customer-orientation is one of emphasis, not exclusivity. All of the utilities that participated in this study consider both DSM technologies and customers' need for, and use of, demand-side technologies or programs. The utilities categorized as technology-oriented generally approach DSM from an engineering mentality, in which technical feasibility and load-shape impacts of various technologies take precedence. In contrast, customer-oriented utilities elevate the importance of customers' needs and attempt to offer DSM programıs to satisfy those needs. For these utilities, concerns about selecting and reaching the target market permeate the program development process. A utility's orientation toward DSM planning can affect the structure of the program development process and, in varying ways, the nature of the programs eventually offered. Some customer-oriented utilities (e.g., Boston Edison and New England Electri: System) offer few programs - each of which encompasses numerous uptions - targeted to specific market sectors. Other customer-oriented utilities (e.g., Madison Gas and Electric) that operate on the basis of market sectors offer many specific programs, at least for selected customer classes. 


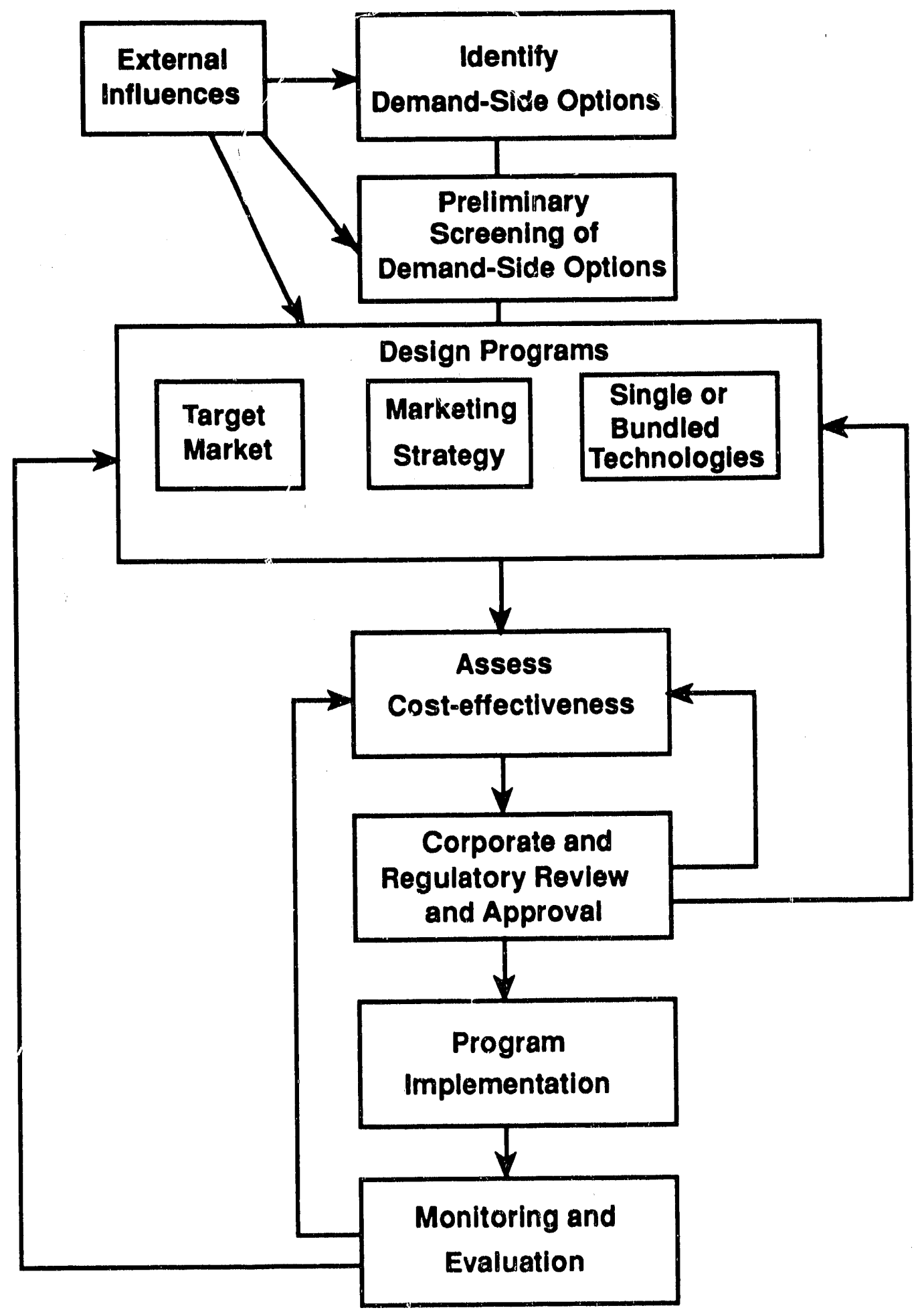

Fig. 3.1. Schematic diagram of technology-oriented DSM program development process. 


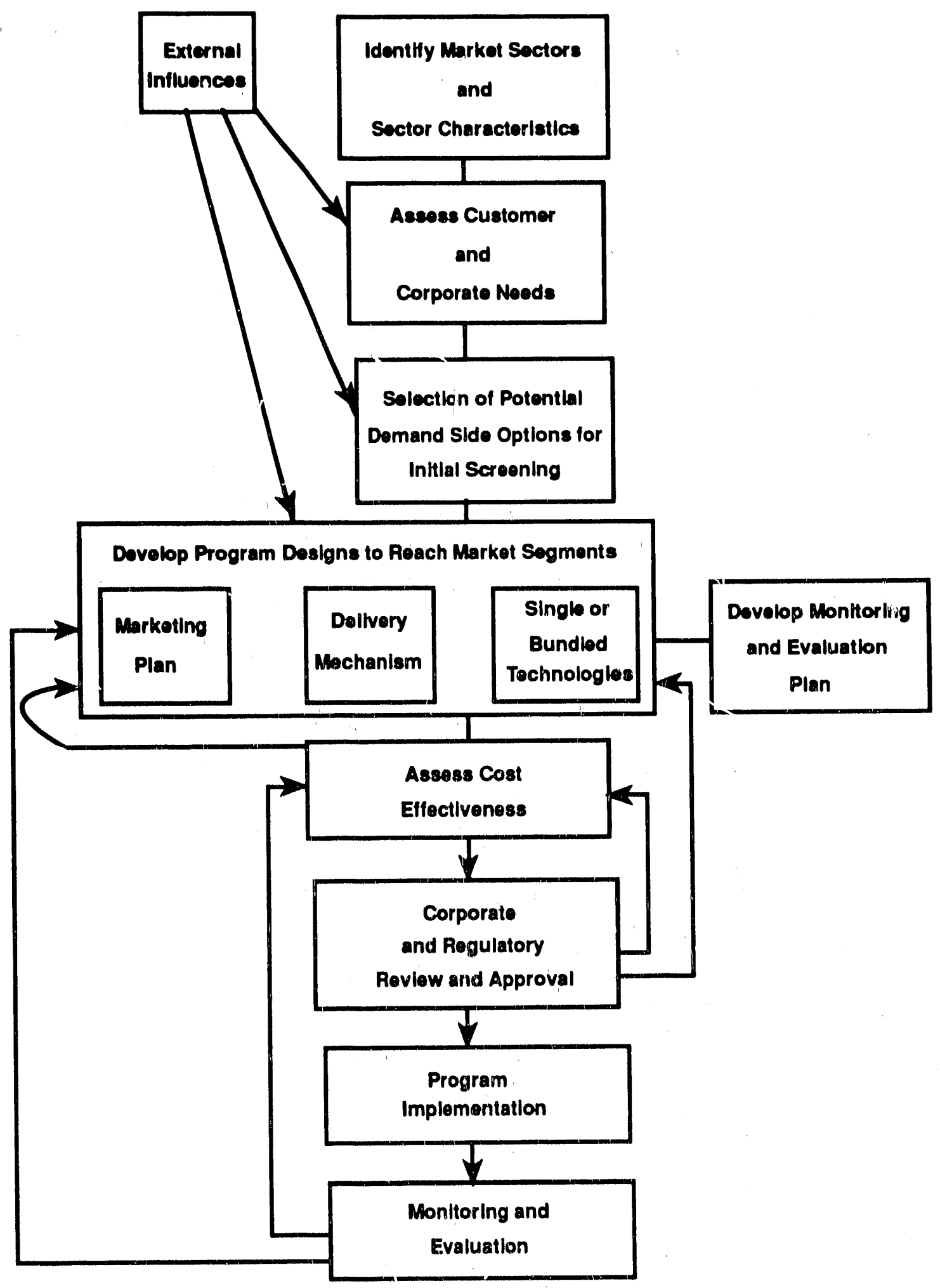

Fig. 3.2. Schematic diagram of customer-oriented DSM program development process. 
As might be expected, the major difference between technology- and customeroriented program development is the nature and placement (during the course of program development) of concerns about technologies, i:ustomers, market segments, and marketing. Technology-oriented utilities start by identifying potential DSOs from a large list of technologies. Such utilities typically focus on technologies primarily in terms of how the technologies can contribute to energy-related goals (e.g., peak reduction, MWh effects). Technologies may be grouped according to end use. Market characteristics generally are considered during the Jesign phase of program development, after technologies have been identified and screened. While program developers may think marketing is critical to the success of programs, marketing may be viewed more as a means of convincing customers to accept programs than as a means of matching customer needs with the utilities' services.

In cortrast, customer-oriented utilities start by identifying market sectors and assessing customer needs. Market sector identification may not occur during each planning cycle; previously delineated market sectors may be used instead. But, knowledge of the market - of customer needs - and judgments about marketability and market acceptance constitute the filter through which the program development process is perceived. Analyses of technologies, while clearly important, are secondary to planners' judgments of what the market wants. Preliminary technology screening typically precedes program design in the customer-oriented DSM program development process (Fig. 3.2). However, one utility (New England Electric System) describes a three-part program design process in which DSO identification and preliminary screening are co-equal with the development of a marketing plan and reviewing delivery mechanisms and marketing plans. Subsuming technology identification and screening in program design indicates that technology is not the driver of the program development process.

\subsection{STAGES IN 'THE PROCESS}

No matter whether a utility adopts a technology- or customer-oriented approach to DSM, the identified stages in program development are similar. However, technology- and customer-oriented utilities vary with regard to the sequence in which stages occur (Figs. 3.1 and 3.2). The following descriptions of DSM program development stages note such differences in sequencing.

External influences on the program development process include the two external factors mentioned in Chapter 2, collaboratives and regulatory pressure (excluding regulatory review and approval). Contacts with, and pressure from, collaboratives and regulators reportedly occur at virtually any stage in the program development process, in either a systematic or ad hoc fashion. Respondents often thought such interactions slow down the program development process and make it more cumbersome because there are more people involved, more meetings, and more negotiating.

Identification of DSOs and preliminary screening refer to the technology identification and screening process that Hill, Hirst, and Schweitzer (1991) outlined in their report. This current study was neither concerned with what technologies were identified nor how they 
were screened, but rather with utilities' inciusion or exclusion of technology screening as a DSM program development stage. While many utilities that participated in this study conducted preliminary assessments of DSOs before they designed their programs, virtually all the respondents regarded preliminary assessments as part of the DSM program development process. Preliminary assessments generally were not viewed as a separate, preceding process. Nevertheless, several respondents indicated that these assessments were not necessarily performed anew each planning cycle; existing documentation on DSOs often was used. Information about DSOs was obtained from varying sources. A few utilities contracted with consultants to compile a list of measures suitable for their service territory. Other ideas were generated in-house, through contacts with other utilities (personal contacts or at conferences), or from written literature. Some utilities (e.g., Puget Power) with mature and comprehensive programs have already completed technology screening; thus, there is less focus on such screening.

Preliminary assessments may consist of rough, per-measure cost-effectiveness calculations, excluding such factors as participation and incentives. Utilities may orient their assessments toward end uses. Some utilities include additional, judgmental screening of technologies according to such factors as the maturity of the technology (how well it is known to work) and the appropriateness of the technology for the utility's service territory. Personnel involved in judgmental screening typically include planners, implementors, and marketing specialists.

Identifying market sectors and market sector characteristics receive varying degrees of emphasis from different utilities. Briefly, identifying market sectors ${ }^{5}$ involves analyzing the customer service area and distinguishing relevant subcategories of customer classes. Some utilities base their categorization on end use (e.g., residential space-heat customers), while others use broader divisions (e.g., New England Electric System's major market sectors are existing commercial and industrial, new commercial and industrial, existing residential, and new residential). The ways market segments are divided may reflect utility preferences for the kinds of programs offered. For instance, New England Electric System offers 12 comprehensive programs, each of which includes numerous measures; the flexibility of its programs matches the breadth of the market sectors it defines. Similarly, Puget Power has broad programs targeted to market segments. While the programs remain intact, the specific measures offered under these programs may vary from one year to the next. Chapter 4 discusses market segmentation in greater detail.

Market sector identification occurs at the beginning of the program development process for customer-oriented utilities and in the program design phase for technologyoriented utilities (Figs. 3.1 and 3.2). Typically, market sectors are not identified during each program development cycle. They are defined with a degree of robustness such that the

\footnotetext{
${ }^{5}$ Respondents at the different utilities use varying terminology with regard to market sectors. Some utilities differentiate between customer class (e.g., residential, commercial, or industrial) and market sectors (e.g., electric hot-water residential or new commercial construction). Other utilities make similar distinctions between market sectors and market segments. We use "market sector" and "market segment" inter'hangeably to indicate homogeneous subunits of customer class.
} 
same categories can be used repeatedly. Likewise, the characteristics of the market sectors may not be re-identified during each planning cycle.

Assessing customer and corporate needs follows market sector identification among customer-oriented utilities. Determining what DSOs customers are likely to need and find acceptable is accomplished by analyzing market sector characteristics, talking to field representatives, drawing from market research (e.g., surveys or focus groups), and using inhouse judgment. Typically, utilities want to identify the minimum amount of cost savings customers desire in exchange for customer efforts and investments required to obtain those savings.

The techniques and processes by which corporate needs are defined (excluding the determination of avoided cost) are much less rigorous than those used to define customer needs. Respondents often mentioned brainstorming sessions. Among the corporate needs that might be established are resource restrictions; goals of providing programs for every customer class; load-shape goals; and the need for a high-visibility, high impact program. Customer and corporate needs then provide the framework within which the remainder of the program development process is conducted.

Program design is an iterative process that uses as its basis the preliminary list of technologies and, particularly for customer-oriented utilities, a sense of customer and corporate needs. At this stage, an idea is elaborated through the following types of activities:

- identify the proposed program's objective (e.g., energy conservation, peak load reduction, or peak shifting), though objectives may not be set formally at some utilities;

- for the utilities that had not assessed customer needs, program designers select their target markets, and virtually all utilities estimate program participation (discussed in Chapter 4);

- decide how to achieve the goals, largely by devising an overall marketing strategy (general approaches to reach customers that include ideas on incentives, promotion, and general delivery mechanisms such as the use of trade allies);

- some utilities suggest marketing techniques (specific ideas such as bill inserts, newspaper advertising, and telemarketing) that can be used, though these strategies often are defined by program implementors later in the process (at some utilities, the implementation or marketing staff determine delivery mechanisms late in the process, after technology bundling decisions have been made and after programs are assessed for cost-effectiveness); 
- decide whether to offer single or bundled technologies as programs or, for utilities like New England Electric System and Boston Edison that offer overarching programs, decide which technologies should be offered in each program; and

some utilities determine how programs will be monitored and evaluated at the same time as the program is developed.

There do not appear to be any formulas for program design. Ultimately, decisions about new program content and form are based on what respondents variously called "judgment," "intuition," or "art." Judgment, in turn, may be based on previous program evaluations (both anecdotal evaluations and statistically based analyses), other utilities' experiences (e.g., another utility with a similar service territory achieving high levels of participation with certain programs), opinions of experienced personnel (e.g., field staff, marketing staff, implementors), and written literature.

Iteration in program design is based largely on internal communications and formal or informal reviews of design concepts. Program designers receive feedback about the accuracy of such items as cost estimates and the likelihood of effective marketing.

The next stage is assessing the cast-effectiveness of programs. Some program components may have been estimated earlier in the program development process. Several utilities reported using in-house computer programs or commercially available software like DSManager to test a program's cost-effectiveness. DSManager is designed to help utilities assess the costs and benefits of DSM alternatives (EPRI 1991). It does so by tracing changes in such physical parameters as annual energy use as well as by tracing the monetary flow different DSOs produce. The program is organized according to customer end use. It employs models of electric systems and their customers to quantify estimates of costs and benefits for each relevant party.

Despite the apparently widespread use of computer programs assessing costeffectiveness and for other purposes, ${ }^{6}$ some respondents were critical of their use. When asked about an ideal DSM program development process, these respondents suggested backing away from complex computer programs, for two related reasons. First respondents questioned the quality of the data that are entered into computer programs. Second, even when accurate data are available, respondents complained that the models' sophistication and precision of results far exceeded the sophistication of the data (i.e., the precision of data) upon which model results rely.

Often, public service commissions dictate what cost-effectiveness test or tests utilities use. The tests used influence resulting cost-benefit ratios. Utilities that use the Total Resource Cost Test, for instance, need not consider the costs of incentives when performing

\footnotetext{
${ }^{6}$ Other commercial models are available for other aspects of DSM planning. For example, the Compreshensive Market Planning and Analysis System, or COMPASS (SRC 1990), is designed to analyze technologies, design and analyze programs, and design and analyze plans.
} 
their evaluations because the fully installed cost of a measure is estimated and results are not affected by who pays those costs. Several utilities use multiple tests; either programs must pass all of them or utilities rely primarily on one test. While several utilities assess the cost-effectiveness of total programs (sometimes resulting in marginally cost-effective or somewhat cost-ineffective technologies passing as part of a larger program), other utilities consider the cost-effectiveness of separate measures.

It is rare for utilities to tinker with their program designs and estimates once the costeffectiveness test or tests have been run. The reason for this practice, according to some respondents, is the time and effort involved in running cost-effectiveness tests.

Corporate and regulatory review and approval generally is the next phase of the program development process. Once planners receive in-house approval of the programs, the programs are described in a written format suitable for submission to the public service commission. This format may entail delineating the terms and conditions of each program. Utilities may write their terms and conditions loosely, to allow flexibility in program implementation. In-house and public service commission reviews can result in further refinements of DSM programs, or in their abandonment.

Program implementation follows regulatory approval. It is at this stage that the final details concerning a program's delivery to the target population are determined. Utilities differ in the extent to which the implementation staff is separate from the planning staff both organizationally and functionally (see Chapter 2). There sometimes is a tension between the implementation and planning staff. For example, several respondents stated that the implementation staff, once given the outlines of a program design and a budget, have much freedom to decide how to implement a program. Sometimes implementors' adjustments to marketing designs create some consternation among planners. Other respondents reported that implementation staff are given strict constraints. For example, at one utility the marketing budget is set before the implementation staff develops the specific marketing plan.

Most of the utilities studied monitor and evaluate the programs they implement. Often, monitoring (collecting data) and evaluating (analysis and assessment) activities begin several years after the first DSM programs originally are offered. Respondents criticized this situation because monitoring and evaluating should provide information useful for developing future programs and refining existing programs; such a time lag can dramatically reduce the usefulness of resulting data. Data on program performance are gathered in a variety of ways, including telephone or mail surveys, focus groups, billing data, and end-use metering. Information may be gathered informally from vendors, commercial and industrial customers, and field representatives, as examples. Evaluation is discussed in more detail in the next chapter. 


\subsection{BASIC CHARACTERISTICS OF THE PROCESS}

Descriptions of DSM program development stages hint at some basic characteristics that underlie the entire program development process. These characteristics are (1) the iterative and interactive nature of the process, (2) its variability, and (3) that the process is permeated by an attitude of flexibility and adaptability.

The iterative and interactive nature of the program development process is very difficult to depict in a diagram. Figures 3.1 and 3.2 show some feedbacks between components, but do not show the strength, frequency; or full extent of interactions. Many of the utilities contacted pursue DSM program development with a team-based approach. The existence of these teams promotes interaction at virtually all stages of program development. Over time, these interactions effectively may become a mechanism through which programs are altered and refined. Furthermore, because the planning process continues after implementation, programs can be related continually.

The program development process is variable for a number of reasons. First, the development process evolves over time, perhaps becoming more standardized. Secondly, at any given time a single utility may take several approaches to program development, varying mainly by who is responsible for developing a given program and the customer class or market segment being served. For instance, team composition, team leadership, and within-team decisions can affect the nature of the program development process in utilities that use a team approach to program development (e.g., Central Maine Power). Some utilities use different program development approaches according to customer class. Third, variation in the program development process is attributable to political pressure (from within or outside the utility) to promote a particular technology or to produce a program with high public visibility. One utility reported a concerted effort to develop a highly visible DSM campaign in the wake of Operation Desert Storm and resulting public concerns about the domestic oil supply. Political pressures may accelerate the program development process, influence the selection of DSM measures, and alter the typical sequence of program development (e.g., a delivery mechanism may be suggested before the program developers begin their work in earnest). And, fourth, variability is evident at some utilities where electricity rates that affect load shape are developed independently of the demand-side planning process. For instance, rates were used to influence load shape before DSM became popular; this practice continues separately from demand-side planning.

There also is an attitude of flexibility and adaptability that permeates the program development process. Several respondents mentioned the need to customize programs between and within customer classes. One utility, for example, offers an umbrella program that allows commercial and industrial customers to propose their own programs, which the utility will implement so long as the programs prove cost-effective. The flexibility of this kind of approach contributes to the lack of formalization and the inability of utilities to document the DSM program development process. 


\section{SELECTED LIETAILS OF THE PROGRAM DEVELOPMENT PROCESS}

This chapter discusses aspects of DSM program development to provide a detailed perspective on four components of the program development process: market segmentation, participation rates, incentives, and program evaluation.

\subsection{MARKET SEGMENTATION}

Market segmentation is the process of dividing a utility's custoriers into subsets that share like characteristics. The degree of subdivision varies according to the nature and number of selected characteristics. This research focused on the market segments a utility used and the bases for choosing particular characteristics to distinguish between market segments.

Utilities employ a range of approaches when defining market segments. The simplest approaches are those that define market segments by customer classes (i.e., commercial, industrial, and residential) or by end-use. Green Mountain Power uses customer class; end uses are used by Duke Power and Madison Gas and Electric. Some utilities (e.g., Potomac Electric Power, Central Maine, and Boston Edison) specifically target low-income populations. More sophisticated market segmentation that groups customers by such characteristics as levels of usage, time of day usage, and socioeconomic level are widely used. Table 4.1 lists the kinds of market segments utilities reported using in the DSM program development process.

Some respondents mentioned that they have moved away from an emphasis on end uses to a broader market segmentation approach (e.g., Boston Edison and New England Electric System). New England Electric System, for instance, offers programs for only four major market sectors: existing commercial and industrial, new commercial and industrial, existing residential, and new residential. These market sectors are distinguished, in part, by the different delivery mechanisms they require. By having only four market sectors, the utility can offer a few broad programs. At both New England Electric System and Boston Edison, the move away from end-uses was motivated in part by the discovery that broad multiend-use programs are easier for customers to understand and use. Customers prefer to be offered several options once rather than being approached several times about independent programs (e.g., upgrading appliances, weatherizing homes, and reducing electricity usage during peak times).

Some utilities use customer classes rather than more finely defined market segments identify customer needs and uses. This approach apparently is influenced by the kind of information on customers that a utility has tracked. Several respondents reported that it is both costly and time consuming to develop systems that track all the desired information on customers. As a consequence, data often are outdated or incorrect. For example, many utilities rely on customers' reports of the electric appliances in their homes. This information typically is gathered during periodic appliance saturation surveys; there is no 
Table 4.1. Selected market segments reported by respondent utilities

\author{
End uses \\ Customer classes \\ Residential retrofit customer \\ Residential new customer \\ Residential customers with natural gas \\ Low-income residential customers \\ Single-family residential customers \\ Multifamily residential customers \\ Retail, nonfood commercial customers \\ Educational facilities
}

incentive for customers to inform the utility about replacement and new appliances. Information on residential end-uses therefore can be poor. Further, as some respondents reported, knowing what customers' end uses are provides no information on behavior and attitudes. For instance, while utilities may know which customers have electric water heaters, they may not know how customers use their water heaters (e.g., for what purpose or time of day or which ones are about to be replaced).

Alabama Power and PSI Energy, Inc. use different kinds of market segments at different times, depending on the nature of particular technologies or programs. These utilities distinguish between market segments according to customer class, demographics, and end uses. Puget Power uses multiple inputs (e.g., demographic information and end-use) in determining its market sectors. For instance, among its market segments are residential new construction and commercial lighting. Puget Power may continue to refine these categories according to information about natural gas availability or demographics (e.g., low-income, multi- and single-family dwellings). As another example, Seattle City Light ties market sector classifications to load forecasting classifications because of the latter group's data needs. Seattle City Light's market segments include office, retail (food or nonfood), education, and health facilities; demographic information seems to play a negligible role for this utility.

Utilities use different sources of information to determine market segments. Some utilities, such as Madison Gas and Electric and Northern States Power, rely largely on traditional demographic information such as SIC codes and, possibly, location (zip codes). Central Maine Power uses a software package that segments customers by zip code combined with information profiling customers' buying behavior and lifestyles (the aggregation of demographic, psychological, and behavioral data is called psychographics). That utility is moving toward a geographic, substation approach, in which customers can be target-marketed according to the characteristics of each substation territory.

One utility originally based its market segmentation on a consultant's study that delineated four or five major segments within each customer class. Number of customers, typical end uses, the homogeneity of the group, and commonality of service methods were 
among the factors the consultant used to distinguish market segments. Currently the utility uses internal judgment to refine its marked segmentation. At other utilities (e.g., Union Electric, Duke Power, and Boston Edison) customer surveys, rate code data, focus groups (with people who are internal or external to the utility), and discussions with field representatives are used to gain information about market segments.

Market segmentation affects the DSM program development process at several junctures. At a minimum, market segments affect how utilities will market their programs. As Chapter 3 discussed, market segmentation is a critical early step in the program development process for customer-oriented utilities. Such utilities screen technologies partly in terms of how technologies can affect particular market segments; they design programs to target market segments and they incorporate schemes (though not necessarily very detailed plans) for reaching those target markets. Technology-oriented utilities typically consider market segments later, at the program design stage (Fig. 3.2). For nearly all the utilities sampled, market segmentation is crucial for marketing and implementation personnel, who need to know what the target market is as well as its characteristics.

\subsection{PROGRAM PARTICIPATION}

Program participation is important to a DSM program's cost effectiveness. But, estimating future program participation (particularly for new programs) is one of the more judgmental aspects of DSM program development. The elemental problem is to predict what people will do. Utility approaches to estimating program participation are classifiable as experiential, theoretical, or goal-oriented. ${ }^{7}$ Utilities sometimes combine approaches or take different approaches to different programs. When using a theoretical approach to estimate program participation, utilities rely more on load forecasting than on experience. Barakat and Chamberlin, Inc. uses a combination of all three approaches. It begins with a theoretical approach that involves collecting data on end-uses and calibrating this information to the utility's long-term forecast. Then, based on planners' experience interpretations of market research, and comparisons of new programs with similar existing programs, the participation rates are estimated or (particularly in New England and the Northwest) a goal for program participation is set.

Utilities relying on an experiential approach may survey prospective customers or hold focus groups to glean appropriate information. This information is difficult to interpret because people usually do not act in accordance with what they say they will do. As an example, years of extensive market research have led Boston Edison's planners to believe that about $20 \%$ of the population will not participate in any DSM program, no matter the technology, incentive, or the ease of acquiring the service or technology. Their maximum realistic cumulative participation rate therefore is $80 \%$. The question then becomes how to

\footnotetext{
${ }^{7}$ Experiential refers to extrapolations from any utility's past experience. Theoretical refers to reliance on non-experiential techniques such as diffusion models and engineering estimates. Goal-oriented refers to a utility's or collaborative's goals for program participation.
} 
determine a more accurate estimate. Boston Edison's planners use their judgment, which is based on observations on participation rates for existing programs, other utilities' experiences, and intuition. Respondents could not give us formulas or general rules they use in estimating program participation. Boston Edison's lack of specificity regarding how program participation is estimated is typical of the utilities contacted. Sometimes, participation over the life of the program (cumulative) was assumed to be a certain figure [e.g., Central Maine Power often uses 50\%, based in part on the findings of Berry (1990)]. Respondents frequently indicated that both cumulative and shorter-term (annual) participation estimates fall in the realm of guesswork or are based on results already achieved by the utility.

Utilities may use as their maximum participation rate the percentage of people who, when surveyed, said they would be willing to participate in a particular program. The survey format may influence the accuracy and usefulness of results. Balasundaram (1991), for instance, proposes three survey formats - focusing on program concepts, program attributes, and a combination of program attributes and willingness to participate - appropriate for different survey objectives. Utilities surveyed for the current research did not specify survey formats. Respondents consistently repeated that surveys overpredict participation because the number of people who participate are far fewer than those who say they will. Nevertheless, utilities may use surveys for their estimates of maximum participation. For the lower bound, some utilities use historical data to determine trends in people's use of the measure under consideration (i.e., a rough idea about how many people currently use the measure). The working estimate of program participation then may become the midpoint between the two estimates.

Additional sources of estimates for utilities with an experiential approach are internal consensus-building techniques (e.g., Delphi methods), staff meetings, field staff experience, post-hoc customer surveys (on other programs), market research to learn more about customers' decision criteria, other utilities, and organizations such as the Electric Power Research Institute. Alabama Power provides an example of how information from other utilities may be used. The utility contacted a dozen utilities (the utilities' names were pulled from literature on the topic) and was sent brochures and historical participation rates. Alabama Power chose to use Florida Power and Light's participation rates because of the similarities in their residential load control programs (Alabama Power Company 1991).

Once there is experience with a program, either through a pilot or full-scale effort, estimating program participation is somewhat easier. Utilities track participation, survey or visit a sample of the participants, and hold focus groups with participants and nonparticipants to obtain data on program participation and on factors that affect participation. Utilities generally extrapolate the information obtained from pilot programs and existing programs to estimate future participation. Here, the problem is that participation rates are not constant throughout the life of a program. Recognizing that there is a "ramping up" of programs over time, some utilities select an arbitrary number of years 
for that process to occur. Niagara Mohawk Power Corporation ${ }^{8}$ states that in developing participation rates, "data and direct experience are limited, and for many programs we had to use judgment to develop reasonable assumptions..." (Niagara Mohawk 1990, p. 3-13).

Estimates of program participation tend to play a role at different times in the planning process. For some utilities (e.g., Potomac Electric Power) the estimates become important primarily at the integrated resource plan stage. Some utilities use such estimates toward the beginning and through the middle of the program design process. Madison Gas and Electric, for example, makes estimates of program participation early, on a technologyby-technology basis, and when programs are being developed. Of course, estimates of program participation will vary according to the incentive being offered. Incentives are discussed in the next section.

\subsection{INCENTTVES}

Utilities' views on incentives ran the spectrum from a preference for providing virtually the total cost of the item to providing as little incentive as possible. Some utilities that prefer full incentives believe that participation will drop dramatically as the level of incentive falls (e.g., New England Electric System). ${ }^{9}$ A put 'ic utility commission is asking New England Electric System to back off of its full incentives to commercial and industrial operations. Particularly for small commercial facilities, the utility is concerned that it would lose a large percentage of its market by asking for customer contributions. In contrast, other utilities that tend to offer full incentives may do so because of external pressure from collaboratives $^{10}$ (e.g., Boston Edison). It is simple to calculate incentives if the utility operates on the basis of full incentives. More difficult is the process of determining incentives among those utilities that want to offer less than a full incentive.

Some utilities use a formula to set incentives. For instance, Union Electric uses a formula that includes one-third of the incremental costs. Puget Power originally offered grants equivalent to zero-interest ten-year loans for the customer; now they base grants on the lower of the net avoided cost and the measure cost adjusted for a customer contribution. Central Maine Power uses a formula approach for commercial customers that offers one cent for every $\mathrm{kWh}$ saved, up to $90 \%$ of the cost of materials. Seattle City Light will pay up to the net present value of energy savings over the life of the measure. PSI Energy, Inc. is moving toward customized incentives that ultimately will be determined by field personnel.

\footnotetext{
${ }^{8}$ We conducted a preliminary telephone interview with this utility.

${ }^{9}$ New England Electric does not take an exclusive full-incentive approach. The utility generally pays for full costs, minus the first year's savings. An exception is new construction measures, for which the utility pays only incremental costs (differences in price between efficient measures and standard measures).

${ }^{10}$ Another form of external pressure is experienced by Seattle City Light. The Bonneville Power Administration sets and provides incentives for some of that utility's programs.
} 
However, field personnel will be using an automated program to help determine what the incentives will be.

For the utilities that neither use formulas nor full incentives, there is a tendency to look first at what the company can afford to pay and then to examine past experience with pilot- or fully-implemented programs. Information drawn from surveys, focus groups, and test programs may be analyzed in lite context of incremental costs, paybacks, and avoided costs.

Most of the incentives utilities offer are variants of a cash rebate. ${ }^{11}$ Types of incentives include cash rebates, bill credits, financing, giveaways, direct installation, design assistance, and rate adjustments. Decisions about the form of incentive offered seem to be a product of internal brainstorming which, in turn, may be influenced by past evaluations. Occasionally, multiple incentives are offered either to test wi,ish one works best or as an addition, when previous incentives were not encouraging the expected participation. For instance, one utility's energy-efficient light bulb program was not producing expected participation rates. Over time, the utility offered additional delivery mechanisms with different incentives. Utilities vary with regard to who is offered incentives. Boston Edison, for instance, tends not to offer incentives to trade allies because its small service territory would make it difficult to know if trade allies are working within their system. Madison Gas and Electric is just starting to work with trade allies, and has not yet offered incentives to them. Alabama Power does not offer incentives to residential customers, because its incentives attempt to sway other decision-makers (e.g., builders).

Incentives are relevant during several DSM program development stages. For instance, incentive levels may be set at the program design phase (e.g., New England Electric System). They also may be considered during preliminary screening and during integration with supply-side resources (e.g., Duke Power), or after technical analyses are completed (e.g., Seattle City Light). Additionally, the form of the incentive may be determined during program design, while the amount of the incentive is specified the end of the program development process (e.g., Potomac Electric Power and Northern States Power).

\subsection{PROGRAM EVALUATIONS}

Program evaluation affects utilities' DSM program development process through the following mechanisms: (1) in utilities' reliance on program evaluation, (2) in the nature and goals of program evaluation, and (3) in the stages of the program development process in which program evaluation plays a part.

\footnotetext{
${ }^{11}$ Some utilities offered loans in the past. But, loans now tend to be de-emphasized or eliminated. Utilities have found loans to be less effective than other incentives, and believe that they involve excessive administrative record-keeping.
} 
The degree to which the utilities that participated in this study relied on the evaluation of previous programs in the process of developing new programs varied tremendously. At one extreme, programs are developed in the virtual absence of evaluation information about past programs because evaluation efforts have just recently been initiated at that utility. At the other extreme is Puget Power, whose DSM program development process now consists primarily of evaluating existing programs to determine what modifications they may require.

The nature and goals of program evaluation influence both tr? stage at which, and the degree to which, process and impact evaluations ${ }^{12}$ affect DSM program development. The following are among the evaluation goals reported by respondents: (1) an overall sense of whether or not to continue a program; (2) cost-effectiveness; (3) the efficacy of various incentive levels, delivery mechanisms, and the like; (4) to provide a basis for estimates of penetration rates and market potential; and (5) to demonstrate energy savings. Evaluations range from the informal and ad hoc to the formal and (more) scientific. Most utilities use multiple evaluation methods, which may include both ad hoc and formalized evaluation techniques. The kinds of evaluations undertaken - both their substance and form - may affect how results can be used in the program development process. Good information about preferences for certain delivery mechanisms according to customer class, for example, contributes to program developers' knowledge base. This knowledge base may be internalized, constituting one basis for "judginent" or "intuition."

Program evaluation also affects the DSM program development process in terms of the stages during which it is considered. The timing of evaluation planning may reflect the degree to which utilities consider evaluation an integral part of the program development process. For a number of utilities, evaluation (assessing and analyzing data) - perhaps together with monitoring (collecting data) - appears at the end of the process. Evaluation goals, and the methods for accomplishing those goals, often are conceived during that final stage of program development. Other utilities stand in marked contrast. These utilities consider how a program will be evaluated at the same time as that program is designed. For instance, Central Maine Power has submitted evaluation plans (of pilot and full-scale programs) to their utility commission along with their program plans since 1987 . Considering evaluation early in the process elevates its importance and ensures that key characteristics of the program can be evaluated. The implication is that evaluation results will feed back into the program development process by refining existing programs and by providing data that offer background for planners' judgments.

\footnotetext{
${ }^{12}$ Process evaluations emphasize how DSM programs operate and how they are delivered. Impact evaluations focus on outcomes of DSM programs, such as their cost-effectiveness and demonstrated energy savings.
} 


\section{SUMMARY AND RECOMMENDATIONS}

This report describes an aspect of DSM that has received little attention, namely, how utilities develop DSM programs. The selection of utilities to study purposely was biased in favor of those with reputations for being experienced DSM program developers so as to optimize the chances to obtain detailed information. Although a small number of utilities that were new to an active program development process also were contacted to learn the basis upon which they decided on particular DSM program development strategies, these utilities did not participate in the study.

The DSM planning process is affected by organizational factors and external influences: (1) the location of the demand-side planning department within the utility; (2) the demand-side planning group's functional responsibilities; (3) upper management participation in the DSM program development process; and (4) the organizational relationship between (or, separation of supply-side and demand-side planning. Organizational factors reflect utilities' views of DSM programs and thus can affect the adoption of a technology- or customer-oriented approach.

Four external influences on utility DSM program development were mentioned by respondents: (1) the use of consultants, (2) intervenor groups, (3) economic conditions, and (4) regulatory policy. These influences do not appear to affect the steps in the program development process. Rather, they alter the amount of time required and, when consultants are involved, the extent to which there is utility involvement in the process.

Written or diagrammatic descriptions of the DSM program development process are scarce. This scarcity is partly attributable to the fact that the process is not linear. Showing interactions and iterations is difficult. Some respondents seemed resistant to specifying a process because they thought descriptions would be too generalized to be useful or too confining to allow for flexibility. Such respondents indicated that, once people are involved in the process, documentation would not be useful. However, other respondents thought that formalizing the program development process would be a good idea; they had developed, or intended to develop, a formalized (and written) description of the program development process.

Despite repeated claims of the uniqueness of the demand-side planning process and its resistance to standardization, two general approaches to program deveiopment were discerned, namely technology- or customer-orientation. Although utilities consider customerrelated and technological factors in their DSM program development process, utilities can be differentiated by their emphasis on one or the other approach. The different emphases result in somewhat different stages of program development. Technology-oriented utilities approach program development from an engineering framework in which technological factors, end uses, and a technology's estimated energy impacts are drivers. Market sector and marketing considerations tend to come into play during program design. Customeroriented utilities tend to operate within a marketing framework. From this perspective, customer needs, market segmentation, and factors influencing market acceptance are drivers. 
Delineating market sectors and customer needs is the first order of business, followed by technology considerations. Further, potential market acceptability seems to be of more concern throughout the customer-oriented utilities' processes than in technology-oriented utilities.

Table 5.1 identifies the key points at which utilities make choices that affect the program development process. Factors such as collaboration and economic conditions were excluded as key decision variables in this table since their influence on program development largely is outside utilities' control. The table provides a guide for a utility's overall orientation toward DSM program development. Although it was beyond the scope of this study to determine an optimal program development process, the key decision points identified (Table 5.1) provide a framework within which the effectiveness of the process can be evaluated.

\section{Table 5.1. Key decisions to be made about the DSM program developmeist process}

Technology- vs. customer-oriented process

Functional responsibilities of demand-side group

- Planning only (possibly including load research and load forecasting)

- Planning and implementation

- Planning, implementation, and evaluation

- Use of consuitants

- Organizational location of demand-side planning

- Reporting to customer service, marketing, finance or regulatory, or corporate planning vice president

- Position vis-a-vis supply-side planning

- Offering a few comprehensive programs vs. many programs each containing few measures

- Interdepartmental team vs. demand-side planners used to develop programs

This study was intended to be a descriptive report of utilities' DSM program development processes, from their perspectives. Two kinds of recommendations resulted from the study. First, there are three recommendations about the process that derive from this research. Second, there are a series of recommendations for future research.

The first process-related recommendation is that utilities should develop written, standardized descriptions of their DSM program development processes. Documentation should be detailed enough for an informed outsider to understand how programs are 
developed, but not so detailed that the written record could constrain the process. Written standardization is useful:

to ensure replicability of the DSM program development process and its results,

- to allow utilities to evaluate the effectiveness of their processes,

- to allow interested parties outside of the planning process (internal and external to the utility) to understand and assess how programs are developed, and

- to bolster the status of DSM within utilities.

Currently, replicability of the DSM program development process largely is dependent on the corporate memory of a few individuals, which may be problematic in cases of keyemployee turnover and because memory is fallible. Written standardization can facilitate the communication of information to employees new to DSM planning and reduce the ad hoc variation among design teams, who often are given free reign in how they develop programs. Written standardization also can aid the evolution of the process by providing a uniform focus for analyzing and improving the process.

Standardization could improve communication about, and evaluation of, DSM programs to entities outside of the particular utility such as regulatory, nonutility, and consumer groups. Standardization also would improve communications among utilities, benefitting utilities new to DSM as well as utilities that are experienced in DSM program development by showing specific aspects of the program development process (such as assumptions made and bases for judgments). Within a utility, upper management may be better equipped to review and justify DSM programs if they can point to a written, standardized DSM program development process. A written and standardized DSM program development process could contribuie to the credibility of DSM within utilities. Ideally, the written record would admit when assumptions are made (e.g., Alabama Power 1991, Georgia Power 1991) and would document the bases for such assumptions.

Two other recommendations aruse from a question asked during telephone interviews, "What is an ideal demand-side management program development process?" One recommendation is to develop faster screening tools than currently are available, tools that require less data and that are not so exacting as existing computer models. Some respondents were dissatisfied with sophisticated computer models because such models require large quantities of data that are time-consuming to produce and because the quality of data are insufficient to warrant sophisticated models that provide very specific answers. Another related recommendation is to conduct more sensitivity analyses than currently are done and to lessen concern about fine detail.

The second set of recommendations revolves around additional research that moves beyond the descriptions of program development processes delineated in this report. Such descriptions are a necessary first step in evaluating the effectiveness of various DSM program development approaches. Another requirement is establishing appropriate 
definitions of effectiveness. Effectiveness can be defined in a host of ways (e.g., costeffectiveness, participation rates, customer satisfaction, regulatory support, public support, or efficiency in developing programs). Defining appropriate measures of effectiveness requires serious consideration. Nevertheless, analyzing DSM program development processes in terms of measures of effectiveness would constitute progress toward developing a contingency model for designing DSM program development processes. This kind of research could explore further the differences between customer- and technology-oriented DSM program development, and correlate such approaches both to utility type and to effectiveness.

The research described in this report depicts different approaches to DSM program development from a utility perspective; future research could investigate further the implications of these differemce. Among the questions follow-on research could address are the following:

- Is either a technology- or customer-or iented approach to program development better than the other (e.g., acciording to any cif the effectiveness measures discussed above)?

- Given the adoption of any one approach, what is the best way to implement that approach?

- Do the practice and results of DSM program development (e.g., organizational structure, portfolio of DSM programs, measures of effectiveness) vary according to a customer- or technology-oriented approach?

- Is there an evolutionary process in utility approaches to DSM program development, starting with a technology orientation and maturing into a customer orientation? (Although not examined in this study, one hypothesis resulting from the research is that a customer orientation is more likely to occur in utilities whose involvement in DSM is more mature.)

Beyond these research questions, future investigations could analyze the DSM program development process from nonutility perspectives. Collaboratives, intervenors, and regulators, as examples, may see the process differently from utilities in terms of program development components, sequences, and interactions. Particularly where the perspectives of utilities and related nonutility entities diverge, researchers could identify both sources of conflict and the consequences of conflict in a number of realms such as communication or the ease of obtaining regulatory approval of programs. 


\section{ACKNOWLEDGMENTS}

We thank the many utility and consulting personnel who provided information for this study. Ellen Angley, Dan Cole, Greg Collins, Lynn Hobbie, Sara Patton, Judy Ray, Ken Seiden, Allan Shub, Glenn Simpson, Mary Smith, Dick Spellman, Tim Stout, Mark Thornsjo, and Mike Weedall were gracious and informative during lengthy telephone interviews.

We particularly thank Ellen Angley, Paul Davis, Kathy Kelly, Frank Hendrigan, Pat McCarthy, Tim Stout, Richard Spellman, Del Reed, Tina Jacques, Scott Bailey, Lynn Goldfarb, and Hassam Haeri for organizing site visits and for taking the time to meet with us.

Numerous reviewers provided constructive comments that enhanced this report. Of course, we take full responsibility for the final product. For their thoughtful comments, we thank Ellen Angley, Jim Gallagher, Ken Seiden, Doug Bauer, Eric Hirst, Tom Shannon, Sue Coakley, Lynn Hobbie, Dick Spellman, Dan Cole, Barry Moline, Tim Stout, Greg Collins, Ralph Prahl, Ed Vine, Martin Cummings, Judy Ray, and Mike Weedall.

At ORNL, Eric Hirst provided continuing guidance and advice. Doug Bauer, Larry Hill, and Marty Schweitzer also advised us during the course of study. Finally, thanks to Judy Burns and Ethel Schorn for patient secretarial support and to Karen Bowman and Bill Clevenger for producing figures during the course of document preparation. 


\section{REFERENCES}

Alabama Power Company 1991, Demand-Side Planning Process, 1991, Birmingham, AL.

Balasundaram, A. 1991, "Using Surveys to Estimate Participation in Proposed Utility Company Programs," Proceedings, Energy Program Evaluation: Uses, Methods, and Results, 1991 International Energy Program Evaluation Conference, CONF-910807.

Berry, L. 1990, The Market Penetration of Energy Efficiency Programs, ORNL/CON-299, Oak Ridge National Laboratory, Oak Ridge, TN, April.

Clarke, R. C. 1989, "Key Steps in Integrating Demand and Supply Side Resources: Process and Policy Issues," Utility Opportunities for New Generation, Symposium sponsored by the Edison Electric Institute, Boston, MA, June 28-30.

Cohen, A. and J. Chaisson 1990, "Least-Cost Doing': Lessons from the New England 'Collaborative," Proceedings, ACEEE 1990 Summer Study on Energy Efficiency in Buildings, American Council for an Energy Efficient Economy, pp. 5.29-5.33, Washington, DC.

Cohen, A. and M. W. Townsley 1990, "Perspectives on Collaboration as Replacement for Confrontation," Public Utilities Fortnightly 125(5): 9-13.

Cowell, S. 1990, "Collaborative Design of the DSM Power Plant," Proceedings, ACEEE 1990 Summer Study on Energy Efficiency in Buildings, American Council for an Energy Efficient Economy, pp. 5.51-5.59, Washington, DC.

Electric Power Research Institute (EPRI) 1989, 1987 Survey of Commercial-Sector DemandSide Management Programs, EPRI CU-6294, prepared by Battelle-Columbus Division, Mount Pleasant, PA.

Electric Power Research Institute (EPRI) 1991, EPRI DSManager User's Guide, Version 1.5, draft, prepared by Electric Power Software, January.

Gellings, C. W., A. S. Hirshberg, and M. V. Williams 1986, "Successful Demand-Side Management: Customer Behavior is the Key," Public Utilities Fortnightly 117(6): 15-21.

Georgia Power Company 1991, A Proposal for a Pilot Residential Air Conditioning Cycling/Interruption Program and a Request for a Demand Side Program Certification Filing, December 6.

Glaser, B. G. and A. L. Strauss 1967, The Discovery of Grounded Theory: Strategies for Qualitative Research, Chicago: Aldine. 
Hill, L., E. Hirst, and M. Schweitzer 1991, Integrating Demand-Side Management Programs into the Resource Plans of U.S. Electric Utilities, ORNL/CON-311, Oak Ridge National Laboratory, Oak Ridge, TN, January.

Hirst, E. 1991, Possible Effects of Electric-Utility DSM Programs, 1990 to 2010, ORNL/CON312, Oak Ridge National Laboratory, Oak Ridge, TN, January.

Hirst, E. and C. Sabo 1991, Electric-Utility DSM Programs: Terminology and Reporting Formats, ORNL/CON-337, Oak Ridge National Laboratory, Oak Ridge, TN, October.

Holt, E. A. 1991, "There's No Such Thing as a 'Simple' Rebate Program," Proceedings: 5th National Demand-Side Management Conference, Building on Experience, CU-73940, prepared by Energy Investment, Inc. for Electric Power Research Institute, pp. 277-280.

Michaels, H., A. Vincent, A. Ornstein, D. Robinson, and E. A. Holt 1991, "Incentive Strategies for Commercial/Industrial DSM: New Approaches, Rationale and Results," Proceedings: 5th National Demand-Side Management Conference, Building on Experience, CU7394, prepared by Energy Investment, Inc. for Electric Power Research Institute, Palo Alto, CA, pp. 275-277.

National Association of Regulatory Utility Commissioners (NARUC) 1988, Least-Cost Utility Planning Handbook for Public Utility Commissioners, Volurie 2, The Demand Side: Conceptual and Methodological Issues, Lawrence Berkeley Laboratory, Berkeley, CA, December.

New York State Energy Research and Development Authority 1990, The Achievable Conservation Potential in New York State from Utility Demand-Side Management Programs, prepared for New York State Energy Research and Development Authority and New York State Energy Office by American Council for an Energy Efficient Economy and New York State Energy Office, Albany, NY, 1064-EEED-AEP-88, November.

Niagara Mohawk Power Corporation 1990, 1991 Integrated Demand-Side Management Plan, Vol. 1, 1991 Long-Range Demand-Side Management Plan, Niagara Mohawk, Syracuse, NY, p. 3-13, July 23 .

Raab, J. and M. Schweitzer, 1992, Public Involvement in Integrated Resource Planning: A Study of Demand-Side Management Collaboratives, ORNL/CON.344, Oak Ridge National Laboratory, Oak Ridge, TN, February.

Robinson, D., D. Jacobson, S. Haselhorst, and G. Reed 1991, "A Case Study in Comprehensive DSM Measure Analysis and Incentive Setting: The New England Electric System Experience," Proceedings: 5th National Demand-Side Management Conference, Building on Experience, CU-7394, prepared by Energy Investment, Inc. for Electric Power Research Institute, pp. 270-274. 
Schweitzer, M., E. Hirst, and L. J. Hill 1991, Demand-Side Management and Integrated Resource Planning: Findings from a Survey of 24 Electric Utilities, ORNL/CON-314, Oak Ridge National Laboratory, Oak Ridge, TN, February.

Schweitzer, M., E. Yourstone, and E. Hirst, 1990, Key Issue in Electric Utility Integrated Resource Planning: Findings from a Nationwide Survey, ORNL/CON-300, Oak Ridge National Laboratory, Oak Ridge, TN, April.

Wall, B. J. and T. M. Giffin 1990, "Connecticu's Collaborative Process Experience: Utility Conservation and Load Management Program for Electrically Heated New Residential Construction," proceedings, ACEEE 1990 Summer Study on Energy Efficiency in Buildings, American Council for an Energy Efficient Economy, pp. 5.201-5.208. 


\section{APPEINDIX A. DESCRIPTION OF PARTICIPATING UTILITIES}

This appendix provides background information on the thirteen utilities that participated in telephone and on-site interviews. As utilities in this study primarily were selected based on their experience with DSM planning, they vary considerably in terms of such characteristics as their location (Table A.1, Fig. A.1), size, attributes of their service territory, as well as their basic DSM-related goals, definitions, and approaches. Information in this appendix is derived from telephone interviews, written documents and on-site interviews.

Table A.1. Utilities participating in this study

Alabama Power Co., Birmingham, AL
Boston Edison, Boston, MA
Central Maine Power, Augusta, ME
Duke Power Co., Charlotte, NC
Green Mountain Power Co., South Burlington, VT
Madison Gas and Electric Co., Madison, WI
New England Electric System, Westborough, MA
Northern States Power Co., Minneapolis, MN
Potomac Electric Co., Washington, D.C.
PSI Energy, Inc., Plainfield, IN
Puget Sound Power and Light, Bellevue, WA
Seattle City Light, Seattle, WA
Union Electric, St. Louis, MO

Notes: Utilities listed in italics also participated in site visits. The city listed is the location of utility headquarters.

Utility involvement in DSM is strongest in the northeastern Uniteri States, along the Pacific coast, and in the upper Midwest. The sample reflects that patteri. (Fig. A.1), except that no utilities in California participated in the detailed telephone interviews. The sample size was too small to draw statistically valid conclusions about the impact of factors such as geographical location, size, population and service territory, and the DSM program development process empioyed.

In keeping with the strategy of sampling experienced utilities (see Appendix B), participating utilities reported substantial experience with DSM planning. They averaged nearly 12 years of experience, though experience ranged from 4 to 17 years. Some of these years of experience originally may not have been labeled DSM; departments often have been reorganized, altering reporting relationships and responsibilities. Earliest efforts were apt to be labeled conservation and load management. In some cases, reorganization reflects historical shifts in utility emphasis, from capacity growth and sales to peak reduction and 


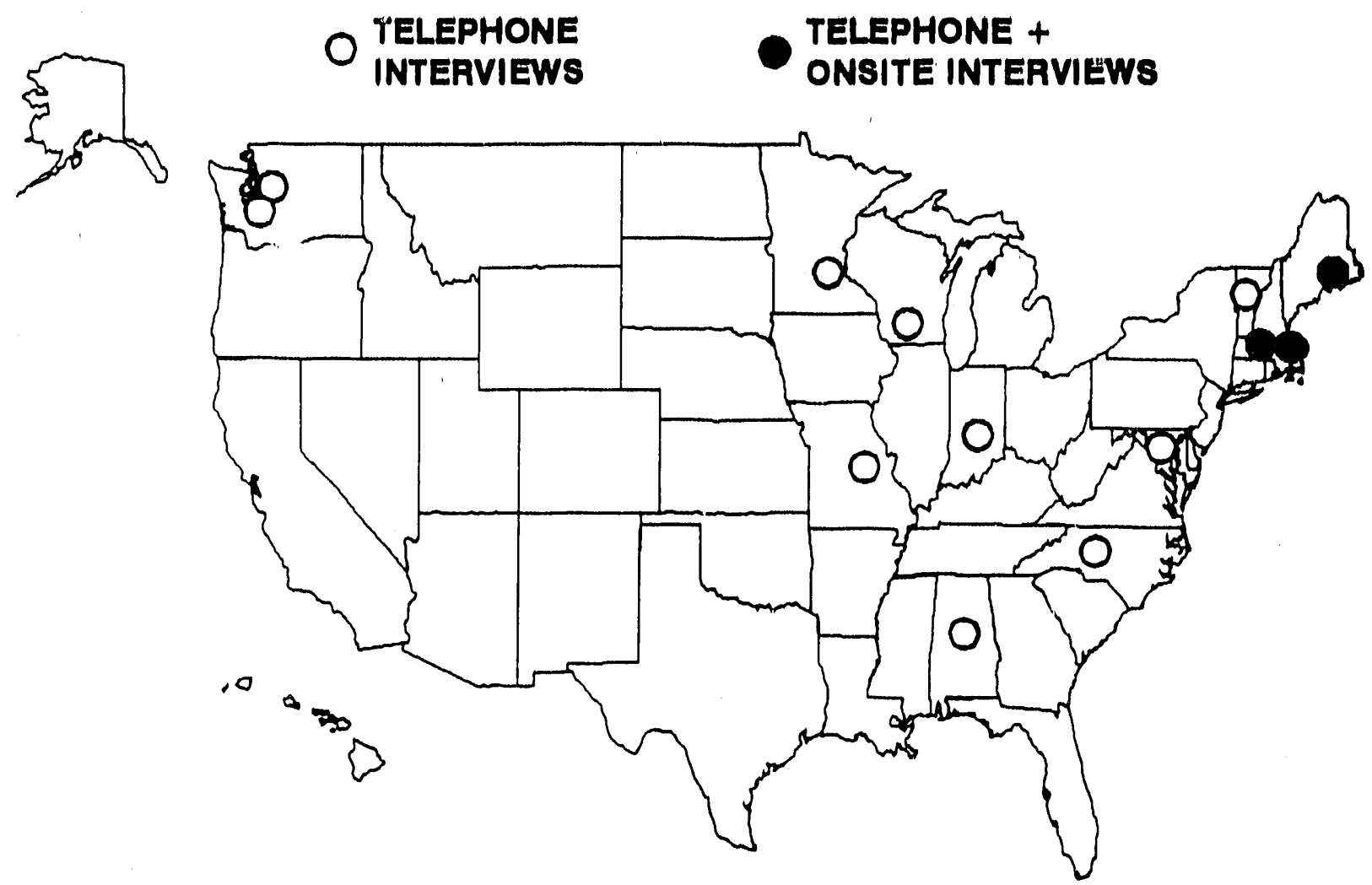

Fig. A.1. Geographic location of participating utilities

energy savings. Several respondents indicated that DSM activities remain unstable with regard to utility focus and organizational structure.

Respondents' definitions of DSM always included peak and energy reduction activities, but only 7 of the 13 respondents also included load building activities. Two of these seven utilities currently are not engaged in load building programs; one respondent stated that load building is not pursued actively, but could result from load shifting. Demand-reduction activities are separated from other DSM endeavors at one utility. In this case, although interruptible rates are intended to reduce demand, they are developed and monitored separately from other demand-side planning activities at the utility.

Respondents' definitions of DSM indicate that utilities are motivated in part by a desire to defer the need for new power plants through energy savings and peak reduction. Another motivation was to increase utility profitability. When asked which characteristics of their utilities and service areas were most important in the development of DSM programs, respondents included the following items:

- public utility commission's and legislators' position on DSM (6 mentions),

- customer preferences and concerns (5 mentions), and

- competition from other fuels (2 mentions). 
Respondents who mentioned the importance of their utility commission's or legislatsis' attitudes toward DSM usually deemed this interest positive. The most obvious commission or legislative impact on utilities occurs when there are mandated DSM goals and through directed funds. For example, since the Pacific Northwest Electric Power Planning and Conservation Act (PL 96-501) passed in 1980, the Bonneville Power Administration has set overall targets for Seattle City Light's conservation savings and pays $75 \%$ of program costs. In only one case was a utility commission reportedly reluctant to advocate DSM programs; the utility is actively trying to transform that reluctance to enthusiasm.

Another strong motivation for active DSM, mentioned by five respondents, was customers' environmental concerns. In particular, customers prefer conservation over new plant construction.

The isle of competition from other fuels in shaping demand-side programs was mentioned twice. In one instance, because the price of natural gas currently is so much lower than electricity prices, the utility decided that it is not cost-effective to offer conservation programs to retain these customers. In another instance, DSM programs must be responsive to the many residential electric space-heat customers who virtually instantaneously can switch heating sources (e.g., wood stoves) without incurring costs.

Two goals that predominated discussions of DSM program objectives were energy savings and peak reduction. About half the utilities primarily seek to save energy; the other half desires lower peak loads. Other, and sometimes secondary, DSM program goals mentioned include increasing customer satisfaction (e.g., Seattle City Light's decision not to build a new substation in a residential neighborhood); satisfying customer preferences; and increasing profitability (Central Maine Power). Another goal influencing the development of DSM programs is the desire for equity among customers (i.e., developing at least one DSM program for each customer class).

Most of the utilities sampled develop DSM programs in-house, though the number of personnel who develop DSM programs varies. Four utilities rely on consultants for program development and four utilities participate in collaborative efforts. Involvement in collaboratives apparently is unrelated to years of experience with DSM planning (Raab and Schweitzer 1992). 


\section{APPENDIX B. RESEARCH METHODS}

Several methods were used to obtain information about DSM program development. Throughout the project, a literature review of energy journals (searching the Electric Power Database, McGraw-Hill Publications On-line, and Trade and Industry Index Database computerized databases) and of reports on topics relevant to DSM program development was conducted. Because there was a dearth of written information about the program development process, most of the information was acquired directly from electric utilities. Although several utilities studied documented the process - including Alabama Power, Boston Edison, Central Maine Power, New England Electric System, and Seattle City Light - the documentation generally was insufficient for the purposes of this report. The program development process typically was not described to the extent that discrete activities and bases for judgments clearly could be identified.

We obtained increasingly more detailed information in a series of contacts with utilities. A preliminary list of utilities to contact was obtained by eliciting suggestions on whom to contact from people knowledgeable about the electric utility industry. Twenty-six utilities constituted this initial list.

Letters mailed to these utilities described study goals, listed topics of particular interest (Table B.1; the topics were drawn from background research), requested the utility's latest DSM plan and other relevant information, and solicited the names of other utilities that are doing a good job of developing DSM programs. Follow-up telephone calls to nonrespondents sometimes resulted in short, open-ended interviews. A total of 17 utilities responded to the initial request, by mailing materials or by talking about DSM program development briefly over the telephone.

Table B.1. Topics mentioned in initial letter

Overall DSM planning process

Estimates of program participation

Program targeting (e.g., by end use, technology, market sector)

Cost estimates (e.g., program costs and program administration)

Net and total energy savings

Criteria used in DSM program development

Role of financial incentives to customers

Improvements in DSM program development process

The protocol ${ }^{13}$ developed for lengthy telephone interviews used a semi-structured interview format. Researchers used their judgment regarding the phrasing of questions, the

\footnotetext{
${ }^{13}$ The protocol is available upon request.
} 
sequence of questions, and the degree to which follow-up questions were asked. The protocol aimed to cover the breadth of issues relevant to DSM program development in as much depth as possible given the constraints of a planned 1-2 hour telephone interview. In practice, the interviews ranged from 45 minutes to over 2.5 hours. Thirteen utilities and one consulting firm participated in the telephone interviews. The consulting firm was selected to provide information on the process that utilities using this consulting firm could not answer themselves. No utilities that were new to the DSM program development process participated in these interviews.

The primary goals for the telephone interviews were the following: (1) to obtain an overview of the DSM program development process; (2) to learn the role of a variety of components (Table B.1) of that process; and (3) to discover the definitions, data sources, judgments, and assumptions surrounding each of the components. Therefore, the protocol was divided into two main parts - general and specific DSM program information. General questions addressed background information about the utility, the utility's history and approach to DSM, an overall description of the DSM program development process (stages of the process and organizational responsibilities), and visions of an ideal DSM program development process. The second part of the protocol asked about the specific topics presented in Table B.2.

Table B.2. Specific topics addressed in telephone interviews

Previous programs and program evaluations

Characteristics of the utility and the area it serves

Market sectors

End uses

DSM technologies

Estimates of program participation

Marketing

Incentives

Total cost estimates

Estimates of energy savings

Cost-effectiveness

No statistical analyses were undertaken on the telephone interview data because of the small sample size and the qualitative nature of the information. Instead, the patterns of response were categorized and summarized. For example, in calculating estimates of total costs, utilities were divided between those including and excluding environmental externalities. More subtle distinctions, such as describing the approach to program development as either experiential or theoretical, also were made. A few of the distinctions among utilities were judged to be fundamental to understanding different DSM program development approaches. Key among these distinctions was the split between those utilities who have a customer orientation versus those with a technology orientation. These distinctions became the themes around which interviews and relevant literature were 
analyzed and interpreted; they influenced data acquisition during subsequent site visits and contributed to the organizational framework of this report. This process of refining the research agenda throughout the course of study, based on interim findings, is termed grounded theory (Glaser and Strauss 1967).

Although they provided significant insights, telephone interviews werc an imperfect data acquisition mechanism for the following reasons:

- the protocol was exploratory, sometimes resulting in a limited depth of questioning;

- respondents, though knowledgeable, may not have known the particulars of all aspects of program development;

- as always in such interviews, respondents may have been hampered by the phrasing of questions (e.g., if they made little sense to respondents, were ambiguous, or superficial);

- DSM program development is a complex process that is difficult to convey over the phone; and,

- respondents tended to focus on specific program descriptions rather than program development processes.

Site visits consequently had three goals. First, they sought to acquire information from all of the players in DSM program development to enhance the picture obtained from one individual. Second, they were used to confirm and elaborate the DSM program development processes gleaned from telephone interviews and written documents. Third, site visits constituted a strategy for collecting very detailed information about a small, select group of topics (market sectors, program participation, marketing, incentives, costeffectiveness, and estimates of costs and energy savings).

Time and financial constraints were important factors in the selection of utilities to visit. Three site visits were made in New England, three to eight hours were spent at each utility. Overall, 12 utility personnel participated in the site visits, including planners, 29 implementors, evaluators, managers, and a vice president. 


\section{INTERNAL DISTRIBUTION}

1. V. D. Baxter

2. L. Berry

3. D. S. Bjornstad

4. M. A. Brown

5. R. S. Carlsmith

6. F. C. Chen

7. J. Christian

8. G. Courville

9. P. D. Fairchild

10. W. Fulkerson

11. M. B. Gettings

12. C. W. Hagan

13. L. J. Hill

14. E. Hillsman

15. E. Hirst

16. P. J. Hughes

17. C. R. Kerley

18. J. O. Kolb

19. M. A. Kuliasha

20. R. Lee
21. P. Leiby

22. J. M. MacDonald

23. V. C. Mei

24. W. R. Mixon

25. S. Purucker

26. D. E. Reichle

27. D. T. Rizy

28. M. Schweitzer

29. R. B. Shelton

30. G. G. Stevenson

31. J. N. Stone

32. J. Van Dyke

33. J. M. Veigel (ORAU)

34. D. L. White

35. T. J. Wilbanks

36. ORNL Patent Office

37. Central Research Office

38. Document Reference Section

39. Laboratory Records (RC)

40-42. Laboratory Records Dept.

\section{EXTERNAL DISTRIBUTION}

43. Bruce G. Buchanan, Computer Science Department, University of Pittsburgh, 206 Mineral Industries Building, Pittsburgh, PA 15260

44. Allan Hirsch, Vice President, Environmental Sciences, and Director, Washington Operations, 5109 Leesburg Pike, Suite 414, Falls Church, VA 22041

45. Martin Williams, Professor, Department of Economics, Northern Illinois University, DeKalb, IL 60115

46. Helen Ingram, Director, Udall Center for Studies in Public Policy, University of Arizona, 803/811 East First Street, Tucson, AZ 85719

47. Calvin MacCracken, President, Calmac Manufacturing Corporation, 101 West Sheffield Avenue, P. O. Box 710, Englewood, NJ 07631

48.-57. OSTI, U. S. Department of Energy, P. O. Box 62, Oak Ridge, Tennessee 37831

58. Office of Assistant Manager for Energy Research and Development, DOE/ORO, P. O. Box 2001 Oak Ridge, TN 37831-8600

59.-750. External Energy Efficiency and Renewables Section Distribution Mailing List and extra copies to E.M. Schorn, 4500N, H-19A 


"
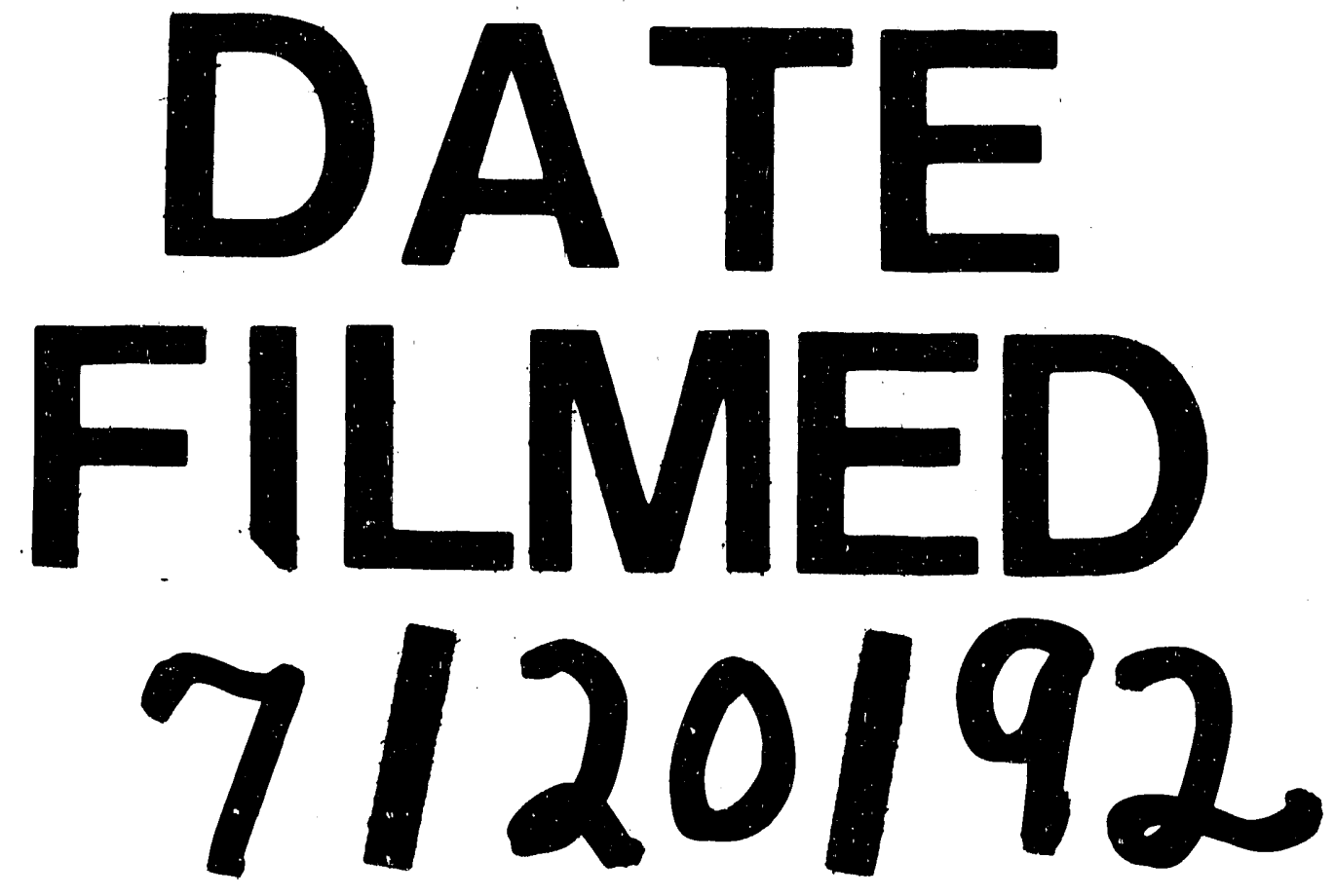
